\title{
HABILIDADE INTUITIVA NO CUIDADO DE ENFERMAGEM ${ }^{1}$
}

Alcione Leite da Silva ${ }^{2}$

Silva AL. Habilidade intuitiva no cuidado de enfermagem. Rev Latino-am Enfermagem 2003 julho-agosto; 11(4):429-35.

Este estudo teve por objetivo compreender a habilidade intuitiva de profissionais de enfermagem no cuidado. $O$ método do estudo foi qualitativo, do tipo exploratório descritivo. A amostra foi composta de 78 membros da equipe de enfermagem do sexo feminino, sendo 31 enfermeiras, 29 técnicas de enfermagem e 18 auxiliares de enfermagem. $O$ resultado deste estudo apontou diferentes níveis de habilidades intuitivas, referentes à iniciante, padrão e veterano. Não foi identificada a relação dos três níveis de habilidades intuitivas com os números correspondentes em anos, encontrados em estudo norteamericano. Os fatores que interferiram na experiência intuitiva estiveram ligados aos fatores ambientais e intra-interpessoais (personológicos). As experiências das profissionais retratam a importância da intuição no cuidado de enfermagem, principalmente em situações de dúvidas, conflito e, nesse sentido, sua função primordial foi a tomada de decisão para a melhor qualidade do cuidado de enfermagem.

DESCRITORES: conhecimento; intuição; empatia

\section{INTUITIVE ABILITY IN NURSING CARE}

This study aimed to understand the intuitive ability of nursing professionals in caring. The study method was qualitative, adopting a descriptive exploratory approach. Sampling involved 87 female nursing professionals, being 31 nurses, 29 nursing technicians and 18 nursing auxiliaries. The result showed different levels of intuitive abilities, related to novice, standard, and veteran. The relation between the three levels of intuitive abilities and the corresponding figures in years, observed in a North American study, was not identified. The factors described as affecting the intuitive experience were both environmental and intrainterpersonal (personological). The experiences of the professionals portrayed the importance of intuition in nursing care, mainly in doubtful and conflicting situations and, in this sense, its vital function was decision-making towards better quality of nursing care.

DESCRIPTORS: knowledge; intuition; empathy

\section{HABILIDAD INTUITIVA EN EL CUIDADO DE ENFERMERÍA}

El objetivo de esta investigación fue comprender la habilidad intuitiva de profesionales de enfermería en el cuidado. Se desarrolló una investigación cualitativa, del tipo exploratoria descriptiva, con una muestra de 78 profesionales de enfermería del sexo femenino, siendo 21 enfermeras, 29 técnicas de enfermería y 18 auxiliares de enfermería. El resultado evidenció diferentes niveles de habilidad intuitiva a saber: iniciante, patrón y veterano. No se encontró relación entre los tres niveles de habilidad intuitiva y los correspondientes números en años, abordados por una investigación norteamericana. Los factores que afectan la experiencia intuitiva en el cuidado de enfermería fueron ambientales e intra-interpersonales (personologicos). Las experiencias de las profesionales retratan la importancia de la intuición en el cuidado de enfermería, principalmente en situaciones de dudas y conflictos, y en este sentido su función principal es la tomada de decisión para mejor calidad del cuidado.

DESCRIPTORES: conocimiento; intuición; empatia

\footnotetext{
${ }^{1}$ Este estudo é parte do projeto de pesquisa "Características do Processo de Vida de Trabalhador/es de Enfermagem de Serviços Hospitalares do Município de Florianópolis"; ${ }^{2}$ Enfermeira, Doutor em Filosofia de Enfermagem, Docente da Universidade Federal de Santa Catarina, e-mail: alcionep@nfr.ufsc.br
} 
INTRODUÇÃO

Nas últimas duas décadas temos observado, na enfermagem norte-americana, interesse crescente pela intuição. A inclusão recente da intuição na enfermagem, como aspecto do pensamento crítico, é significativa para validar a efetividade desse método de "conhecimento", o qual tem função importante no desenvolvimento do conhecimento de enfermagem ${ }^{(1)}$. A intuição tem sido considerada componente importante no julgamento clínico e na tomada de decisões, sendo, portanto, imprescindível para uma maior qualidade do cuidado de enfermagem ${ }^{(2)}$. A intuição é instrumento cognitivo importante que pode ser usado por indivíduos e grupos com vistas a encontrar soluções para problemas complexos na prática clínica, gerenciamento, educação e pesquisa em enfermagem ${ }^{(3)}$.

$\mathrm{Na}$ literatura da enfermagem norte-americana, estudos apontam para posições diferentes acerca da definição da intuição. Nesse sentido, a intuição tem sido definida como conhecimento e sentimento que possibilita a tomada de decisão sem o recurso do processo analítico consciente $^{(4)}$. Outros estudos apontam a intuição como um tipo de conhecimento e como um modo de pensamento $^{(5)}$. O conhecimento atribuído à intuição tem sido baseado no reconhecimento de um padrão global, de totalidade, a partir de informações complexas ${ }^{(3)}$.

Apesar do crescente número de estudos sobre a intuição, ainda há pouca clareza na sua definição, bem como na articulação e explicação de sua origem e manifestação ${ }^{(6)}$. Lacunas ainda persistem acerca da compreensão deste conceito ou como ele é usado na prática de enfermagem ${ }^{(6)}$.

$\mathrm{Na}$ literatura da enfermagem brasileira há uma lacuna significativa de estudos que busquem investigar a natureza do conhecimento intuitivo e sua função no cuidado de enfermagem ${ }^{(7)}$. Os poucos estudos encontrados descrevem experiências com a intuição no cuidado de enfermagem $^{(8-9)}$. O processo intuitivo, enquanto fenômeno de qualidade criativa e de síntese, tem sido considerado imprescindível na prática do Cuidado Transdimensional, tendo sido incluído no padrão de experiência interior desse paradigma $^{(9)}$.

Considerando as lacunas existentes em nossa realidade acerca de estudos sobre o conhecimento intuitivo, a importância desse no cuidado de enfermagem, aliados ao meu interesse pelo tema, optei pelo estudo em questão, que teve por objetivo compreender a habilidade intuitiva de profissionais de enfermagem no cuidado. Nesse sentido, as questões da pesquisa foram: como as profissionais de enfermagem experienciam a intuição no cuidado de enfermagem? Há alguma relação entre habilidade intuitiva e experiência profissional?

\section{REFERENCIAL TEÓRICO}

Estudos evidenciam que enfermeiras progridem no uso da intuição através de uma seqüência de habilidades adquiridas, que vai de iniciante para a expert ${ }^{(10)}$. A enfermeira expert é capaz, com base em sua intuição, de discriminar os componentes essenciais de um problema e relacioná-los às questões mais amplas. Ela captura a gestalt da situação e prossegue a partir de mudanças sutis e vagas nas condições de clientes. A expert não se baseia somente em sua intuição, mas também não as ignora. Posteriormente, foi demonstrado que o julgamento intuitivo é o que distingue a expert da iniciante na enfermagem ${ }^{(3)}$.

Outro estudo evidenciou relação direta da habilidade intuitiva com a experiência das enfermeiras, tendo detectado três níveis de intuição, denominados iniciante, padrão e veterano ${ }^{(11)}$. No nível de experiência iniciante, que abrange o período de um a dois anos de experiência, as informantes comentaram suas inabilidades para confiar em suas intuições, expressando suas esperanças em realizá-la no futuro. No nível padrão, de três a oito anos de experiência, as informantes manifestaram um sentido de autoconfiança em identificar, reconhecer, focalizar e confiar na intuição em sua prática. No nível veterano, informantes, de oito ou mais anos de experiência, não pararam para pensar em reconhecer as intuições ou demonstraram preocupação em confiar nelas. Nesse nível, a intuição apareceu como habilidade inata para o uso no cuidado de enfermagem.

Alguns fatores têm sido descritos como afetando a experiência da intuição no cuidado de enfermagem, tais como os fatores ambientais e intra/interpessoais (personológicos) $)^{(11)}$. Os fatores ambientais incluíram: (a) o estado do paciente, (b) o grau de apoio técnico disponível na unidade (equipamentos e recurso humano), (c) o nível de atividade, sobrecarga sonora e distração na unidade (estímulo externo) e (d) filosofia organizacional. De acordo com as informantes, pacientes em estado grave estimularam mais a consciência intuitiva na enfermeira. A intuição também é relatada como mais necessária em situações em que há menos recursos humanos e técnicos. As informantes também relataram que quanto maior 0 estímulo externo, mais necessária era a intuição. A 
existência de maior estímulo externo, contudo, dificultava a experiência intuitiva. Foi também detectado que filosofias organizacionais que apóiam a independência e autonomia favorecem o uso da intuição no cuidado de enfermagem.

Os fatores personológicos encontrados foram: (a) a qualidade da relação enfermeira-cliente, (b) o estado físico e psicológico, (c) autopercepção de ser respeitada pelos seus pares e pelos médicos e $(d)$ imagem profissional. A habilidade da enfermeira em estabelecer relação mais profunda com clientes, influenciou a quantidade e a qualidade da intuição nas situações vivenciadas. O uso da palavra profunda não estava ligado ao tempo de contato com clientes. A fadiga física e emocional prejudicou a experiência intuitiva. Por outro lado, o bom relacionamento com colegas e médicos favoreceu a expressão de suas intuições, fazendo-as se sentirem mais confortáveis em falar sobre suas experiências. A intuição foi freqüentemente relacionada à imagem profissional de uma excelente profissional, sendo desenvolvida com a experiência no cuidado.

Com base em testes de personalidade demonstrou-se que as pessoas intuitivas tendem a ser: não convencionais e à vontade nessa situação, confiantes, auto-suficientes, emocionalmente envolvidas em questões abstratas, em termos intelectuais ou acadêmicos, ou em valores humanos, dispostas a explorar incertezas e considerar dúvidas e capazes de fazê-lo sem medo, dispostas a se exporem a críticas e desafios, capazes de aceitar ou rejeitar as críticas quando necessário, dispostas a mudar quando consideram apropriada a mudança, resistentes a controle e direcionamento externo, independentes, previdentes e espontâneas ${ }^{(12)}$.

A intuição emerge da sinergia entre conhecimento, sentimento e experiência ${ }^{(6)}$ e, nesse sentido, é fenômeno observável, mensurável, podendo ser desenvolvido através da educação e prática ${ }^{(13)}$.

\section{METODOLOGIA}

Este estudo foi desenvolvido com base no método qualitativo, do tipo exploratório-descritivo. Esse tipo de estudo é geralmente usado para compreender as características de determinado campo de estudo, com o objetivo de retratar a situação como ela naturalmente acontece e fornecer dados para o desenvolvimento de outros estudos $^{(14)}$. O projeto do estudo foi aprovado pelo Comitê de Ética em Pesquisa com Seres Humanos, da
Universidade Federal de Santa Catarina. O seu desenvolvimento ocorreu após detalhada explicação dos propósitos do estudo e assinatura do consentimento livre e informado pelas participantes, tendo sido assegurado o anonimato e a confidencialidade das informações obtidas.

A amostra foi composta de 78 profissionais de enfermagem do sexo feminino, sendo 31 enfermeiras, 29 técnicas de enfermagem e 18 auxiliares de enfermagem, que espontaneamente se prontificaram a participar do estudo. A amostra representou 13 unidades de internação de três serviços hospitalares de Florianópolis. O estudo incluiu profissionais de enfermagem que atuam na prática clínica da enfermagem. A idade das profissionais variou entre 23 e 52 anos, sendo que, para as enfermeiras, a maioria (23) se concentrou na faixa de 23 a 37 anos, para as técnicas essa faixa se ampliou para 42 anos (26), e para as auxiliares a concentração se deu na faixa de 33 a 47 anos (13). O tempo médio de experiência prática das enfermeiras, técnicas e auxiliares de enfermagem foi de 8, 7 e 5 anos, respectivamente.

A coleta das informações foi realizada através de entrevista individual em sala privada do hospital, apoiada nas seguintes questões: Conte-me uma ou mais situações de cuidado de enfermagem em que você se deixou guiar pela intuição de clientes. Conte-me uma ou mais situações de cuidado de enfermagem em que você utilizou sua intuição.

As entrevistas foram gravadas com a permissão das participantes e, posteriormente, transcritas. A análise dos dados foi precedida de leitura exaustiva e cuidadosa do conteúdo das entrevistas e efetuada com base na combinação e na categorização das informações, seguidas da identificação de padrões ${ }^{(15)}$. Com vistas a manter o anonimato, as falas das participantes foram identificadas pelos seguintes códigos: Enfermeira - E, Técnica de Enfermagem - TE, Auxiliar de Enfermagem - AE, acompanhados dos números de identificação das mesmas. A análise foi norteada pelas questões da pesquisa e apoiadas no referencial teórico.

\section{RESULTADOS E DISCUSSÃO}

Ao descreverem suas experiências, as profissionais de enfermagem evidenciam diferentes níveis de habilidades intuitivas, que apontam para a classificação referente à iniciante, padrão e veterano ${ }^{(11)}$. Em relação ao nível de iniciante, verifiquei maior prevalência para as 
enfermeiras (15) e técnicas de enfermagem (13), sendo menor para as auxiliares de enfermagem (5). Quanto ao nível padrão houve destaque para as técnicas de enfermagem (10) em relação às demais profissionais. No nível veterano prevaleceram as auxiliares de enfermagem (8). Houve predominância para o nível iniciante (33), seguido do padrão (22) e do veterano (16). A predominância dos níveis mais elevados de habilidades intuitivas para as auxiliares (veterano) e as técnicas de enfermagem (padrão), em relação às enfermeiras, pode estar ligada ao fato de que os níveis técnicos de formação não são equivalentes ao nível universitário. Conseqüentemente, as auxiliares e técnicas de enfermagem estão sujeitas a menor tempo de formação e, portanto, menos expostas ao discurso científico.

As participantes, com habilidade intuitiva iniciante, demonstraram dificuldades em confiar em suas intuições. A habilidade padrão manifestou-se através de autoconfiança na intuição, tendo sido freqüentemente referido que as experiências, principalmente aquelas mais marcantes, foram fontes de aprendizagem. Aquelas que evidenciaram a habilidade de veterana declararam que a intuição é um processo natural, inato. Essas profissionais sentiram-se confortáveis em falar de suas experiências e as usam independente de serem consideradas não científicas, ou de serem desacreditadas pelas colegas, como exemplificado na Tabela 1.

Tabela 1 - Exemplos de descrições relacionadas aos níveis de habilidades intuitivas, fornecidas pelas participantes do estudo (Florianópolis, 2000)

\begin{tabular}{cl}
\hline $\begin{array}{c}\text { Niveis de } \\
\text { habilidades } \\
\text { intuitivas }\end{array}$ & \multicolumn{1}{c}{ Descrições } \\
\hline Iniciante & Às vezes eu falho, às vezes a intuição diz para mim \\
& uma coisa e eu não a sigo, mas geralmente uso. Eu \\
& tento dar bastante atenção a isto. Só que às vezes a \\
& gente falha nesta hora (E1). \\
& $\begin{array}{l}\text { É difícil saber se a sensação é realmente uma intuição } \\
\text { e, se não se domina muito bem, passa despercebida ou }\end{array}$ \\
& nem modifica o acontecimento se não a intuísse (E3). \\
& Eu observo, fico observando para ver se realmente é \\
& real (AE4). \\
& Eu uso muito a intuição. Antes, às vezes, aconteceu de \\
& não dar atenção, isto marcou (E9). \\
& No início da profissão era muito técnica, seguia as \\
& regras. Após anos de trabalho e experiência a gente \\
& muda e consegue ouvir melhor (E20). \\
& É como eu te falei, eu acabo tendo estes momentos, \\
& mas são tão automáticos que não percebo (E28). \\
& Eu disse, ele vai complicar e complicou...eu falo, eu \\
falo, toda vida , inclusive para os médicos, eu digo tem & que ser rápido, na verdade eles nem sempre aceitam a \\
opinião, mas eu falo, eu dou, eu digo tudo que é para o \\
bem do paciente, eu faço, eu vou à luta se acham \\
errado ou não.. (AE14).
\end{tabular}

Não detectei, nesse estudo, a relação entre os três níveis de habilidades intuitivas e os números correspondentes em anos, encontrado em estudo norteamericano ${ }^{(11)}$. Embora o nível iniciante tenha correspondido à faixa de um a dois anos, nesse estudo, essa faixa variou para as enfermeiras de 3 a 22 anos, para as técnicas de enfermagem de 4 a 27 anos e para as auxiliares de enfermagem de 4 a 37 anos. Em se tratando do nível padrão, proposto de 3 a 8 anos, verifiquei que, para as enfermeiras, a faixa era de 5 a 20 anos, para as técnicas de 6 a 23 anos e para as auxiliares de 8 a 9 anos. Já com relação ao nível veterano, correspondente a oito ou mais anos, encontrei para as enfermeiras a faixa de 6 a 17 anos, para as técnicas de 1 a 27 anos e para as auxiliares de 6 a 23 anos. Nesse sentido, a menor manifestação das participantes nos níveis veterano e padrão para habilidades intuitivas e as faixas de anos maiores, detectadas em nossa realidade, podem estar relacionadas à ausência desse tipo de conhecimento nos currículos dos cursos de enfermagem específicos, ao discurso dominante da cientificidade do conhecimento teóricoprático, à lacuna considerável de estudos na literatura abordando o tema, bem como à desvalorização desse conhecimento pelo meio profissional, inibindo, portanto, 0 seu desenvolvimento e expressão.

A influência da intuição na prática pode depender do seu reconhecimento e da confiança adquirida com o seu uso repetido ${ }^{(16)}$. Na realidade norte-americana, estudo evidenciou que quando as enfermeiras começam a confiar em suas intuições (por exemplo, quando elas avaliam um cliente e sabem que a sua condição está piorando, sem sinais físicos evidentes), elas podem se sentir frustradas se o médico nem sempre confia em suas impressões ${ }^{(17)}$. Outro estudo também constatou que a experiência em fazer um julgamento profissional intuitivo parece desconcertante para muitas enfermeiras, tendo em vista ser essa considerada uma atitude não profissional ${ }^{(18)}$. Esses dados apóiam a afirmação de que enfermeiras experientes apontam suas intuições como uma dimensão valiosa de seu julgamento clínico, mas elas somente falam sobre esse assunto com colegas de mente aberta ou com aquelas que se arriscam a relatar experiências similares ${ }^{(19)}$.

Verifiquei que as profissionais que utilizam suas intuições no cuidado de enfermagem não se baseiam somente em suas intuições ou nas de clientes, mas buscam evidências clínicas para apoiá-las, seja no prontuário, junto às colegas e aos familiares, resultado esse embasado por estudo norte-americano ${ }^{(10)}$. 
Os fatores que interferem na experiência intuitiva, descritos pelas profissionais deste estudo, estiveram ligados aos fatores ambientais e personológicos, conforme exemplificado na Tabela 2. Os fatores ambientais incluíram o estado do cliente, o grau de apoio técnico disponível na unidade (recursos humanos), o nível de atividade e a filosofia organizacional. A maior freqüência de experiências intuitivas apareceu ligada a clientes em estado grave. Por outro lado, o menor número de recursos humanos, gerando sobrecarga de trabalho, bem como a rotina hospitalar, que limita a autonomia profissional, foram apontados como afetando negativamente a experiência intuitiva.

Em relação aos fatores personológicos, destacam-se: a qualidade da relação profissional-cliente, o estado físico e psicológico e a imagem profissional. As relações de maior proximidade e o estabelecimento da empatia favoreceram as experiências intuitivas, ao passo que o desgaste físico e emocional interferiu negativamente na intuição. A maior capacidade técnico-científica favoreceu a expressão das intuições e a maior credibilidade por parte da equipe de saúde. O tempo de experiência profissional emergiu, com freqüência, como fator positivo.

Tabela 2 - Exemplos de descrições relacionadas aos fatores ambientais e personológicos, fornecidos pelas participantes do estudo (Florianópolis, 2000)

AMBIENTAIS

Estado do cliente

Grau de apoio técnico Nível de atividade

Filosofia organizacional

\section{PERSONOLÓGICOS}

Relação profissional-cliente

Estado físico e psicológico

Imagem profissional

Tempo de experiência
Não é no comportamento do paciente, mas na minha intuição, eu acho que ele não está bem, tu sempre fica apreensiva. Tu volta e meia faz alguma coisa, mas tu vai lá...tu vê que ele está decaindo, tu está vendo que ele vai morrer, tu fica apreensiva, tu chamas o médico (AE3).

Lembro de uma paciente que não estava bem, estava angustiada, os sinais vitais estavam normais. No momento ela estava bem, mas senti que ela estava estranha. Eu sei que depois ela começou a agravar (AE17).

Quando tem mais gente para trabalhar fica mais fácil de ouvir (AE5).

O nosso trabalho é corrido e dificulta a intuição (TE13).

Mas na maioria das vezes, a gente deixa fugir um pouquinho, é muito trabalho (TE2).

Sempre utilizo, como já disse, quando eu posso, sem interferir no andamento, na rotina de trabalho (AE6). Quando não interfere nas rotinas eu levo em conta (TE28).

Acho que a intuição é dificultada pelas normas do hospital e da unidade (TE28).

Quando eu me envolvo com ele, quando tu vês o paciente, tu não podes ver só o corpo do paciente, é necessário ver o sentimento, as necessidades, a vontade, acho que neste relacionamento tu consegues sentir, sentir até o que o paciente está querendo (E31).

Precisa conhecer um pouco mais o paciente para sentir melhor (TE12).

Quando estou bem comigo mesma, eu consigo fazer isto melhor (E18).

Claro que tem dias que eu não estou muito bem comigo mesma (AE17).

Em nível hospitalar, a intuição terá benefício se você tiver conhecimento científico, pois só irão acreditar nas suas sugestões se confiarem profissionalmente em você (E2).

Após anos de trabalho e experiência, a gente muda e consegue trabalhar melhor (E20).

Intuir algo é uma coisa que vem embutida na tua experiência e nas vivências anteriores, sejam elas pessoais ou profissionais e quando tu tens vem espontaneamente, vem rápido (E25).
Os fatores encontrados foram também apoiados por outros estudos. Um deles demonstrou que as enfermeiras que aprendem a cultivar as suas habilidades intuitivas, necessitam tornarem-se mais eficientes em sua função, para que possam ter crédito ${ }^{(17)}$. Outro estudo, realizado com enfermeiras de unidades de cuidado intensivo neonatal, evidenciou quatro fatores que estimulam as experiências intuitivas: maior tempo de experiência e eficiência técnica, maior envolvimento com a criança, atenção às "pistas" identificadas nas crianças e a ligação das percepções presentes com as experiências passadas $^{(20)}$.

Neste estudo, as experiências intuitivas provenientes de clientes estiveram, na sua maioria, ligadas às situações de estado grave, tendo sido destacadas aquelas situações em que eles ou elas referiram que iriam morrer, o que acabou por acontecer. Alguns chegaram até a especificar o dia e solicitaram a presença dos familiares. Outras situações ocorreram com clientes que sentiam que iam morrer na cirurgia e exames, o que de fato ocorreu. Foram destacadas outras situações com clientes agonizantes por diversos dias e que vieram a óbito logo depois da chegada do familiar que estavam aguardando. Também ocorreram situações com clientes que tiveram intuições ruins acerca dos resultados de exames e essas foram confirmadas. Alguns exemplos descritos são apresentados a seguir.

...já teve vários pacientes que relataram, por exemplo, na neurocirurgia, um paciente dizia assim para gente: eu vou morrer, enfermeira avisa meus familiares, liga pra eles que eu vou morrer. 
Conversando, falei: o senhor fica calmo, o senhor está um pouco triste. Não enfermeira, eu vou morrer. De repente houve piora do quadro do paciente e ele foi a óbito. Ele não estava tendo dispnéia, não tinha sinais que poderiam levá-lo a óbito De repente piorou o quadro dele e ele foi a óbito, isso não aconteceu só uma vez (E10).

A semana toda uma paciente disse pra mim que sentia não ser uma coisa boa o que tinha. Veio o resultado e realmente não era (E12).

Às vezes tem aqueles pacientes graves, principalmente da pneumologia, eles dizem: eu vou morrer e realmente eles morrem. Às vezes a gente até chama o médico e diz olha vem rápido que o paciente disse que vai morrer e acontece deles irem a óbito (TE26).

Geralmente a gente presencia muito no pré-operatório, 0 paciente fica ansioso e diz que vai morrer. Falamos que vai dar tudo certo para ele, damos apoio e segurança para ele, confortamos ele. De repente, o paciente demora, a gente sabe que ele foi para a UTI (AE3).

Por exemplo, o paciente diz que tem necessidade de falar com alguém. Então tenho aquela intuição de que vai acontecer alguma coisa e que a gente deve fazer na hora e se não faz se arrepende. Porque, às vezes, não dá mais tempo, porque a morte chega e você não deu atenção à intuição dele (AE5).

Eu lembro uma vez que uma paciente solicitou muito que um familiar permanecesse naquela noite para pousar no hospital com ela, mas a familiar não pôde. No final da tarde avisei a enfermeira que a paciente não estava se sentindo bem e pedia a presença do familiar. Então, eu liguei para esta pessoa e ela se dispôs a vir para o hospital. Naquela noite a paciente faleceu (AE6).

As experiências intuitivas das profissionais relacionaram-se à proximidade do óbito, não só de clientes graves, mas também daqueles em que não havia possibilidade para tal ocorrência. Outras situações estiveram ligadas à intuição da necessidade e complicações apresentadas por clientes, à tomada de decisões clínicas ou administrativas, como evidenciam os depoimentos a seguir.

...teve uma paciente que estava ruim; ela estava depressiva; ela não pediu porque ela não se comunicava, mas eu senti que deveria telefonar para um filho dela e o filho veio vê-la. E a paciente deu uma estabilizada (E1).

Teve outra também que a paciente estava agonizando vários dias, entre a vida e a morte, e senti que ela estava esperando alguém para se despedir dela, e veio um filho dela de longe, depois logo em seguida ela morreu (E1).

Um dia desses chegou um paciente na emergência, considerado pelos familiares em estado de coma. Aí, eu chegando junto dela, pensei, essa mulher é diabética e sem pensar e sem prescrição médica eu colhi uma glicemia e ela estava com uma taxa elevada. Foi uma intuição que eu tive no momento, depois que eu fiz eu comuniquei ao médico. Assim, pelo menos, o paciente se recuperou em seguida (TE3).

Vários exemplos. No isolamento, puncionei uma veia sem estar prescrito, por achar que a criança estava se agravando. Comuniquei o plantão da gravidade da criança. Ele achou que estava tudo bem e a criança complicou (TE15).

Sim, às vezes a gente pensa que eles estão chamando, mas não chamaram, e a gente vai e realmente estão precisando da nossa ajuda (AE4).

A última paciente grave que nós tivemos aqui foi a óbito. Estava na hora do almoço, eu disse: vou almoçar porque são 11 h30min, ... , parece que alguém está me chamando, aí fui no 702 e a paciente estava parando (AE4).

$E u$, às vezes, pressinto que o paciente está passando mal, que está precisando de ajuda; às vezes não pode falar, porque é um paciente grave, está com traqueostomia, e eu tenho uma intuição que ele está precisando de ajuda (AE11).

Essas experiências são descritas como marcantes, gerando impactos "profundos" nas crenças e valores das participantes que estão começando a ouvir suas intuições, principalmente quando elas se repetem. Muitas referem que começaram a prestar mais atenção às suas próprias intuições a partir das experiências de clientes. Como resultado, elas referem que ficam mais sensíveis às intuições dos clientes, procurando estar mais alertas quando essas são expressas.

\section{CONSIDERAÇÕES FINAIS}

Neste estudo, as experiências das participantes oferecem indicações claras da importância da intuição no cuidado de enfermagem, principalmente em situações de dúvidas e conflitos. Nesse sentido, a função primordial da intuição tem sido a de nortear a tomada de decisão para uma ação mais efetiva. Ao descreverem suas experiências, as participantes evidenciam diferentes níveis de habilidades intuitivas, que apontam para a classificação referente à iniciante, padrão e veterano ${ }^{(11)}$. No entanto, não há evidências sobre a relação dos três níveis de habilidades intuitivas com os números correspondentes em anos, encontrados em estudo norte-americano ${ }^{(11)}$. Os fatores que interferiram na experiência intuitiva das participantes deste estudo estiveram ligados aos fatores ambientais e personológicos.

Os resultados dos estudos citados na discussão, 
bem como os deste em particular, parecem apontar para o fato de que a intuição transcende a cultura, sendo fenômeno humano e universal. Em nossa realidade, dadas as lacunas existentes acerca desse tema, estudos se fazem necessários, com vistas a aprofundar o conhecimento sobre a intuição e a sua expressão no cuidado de enfermagem, bem como apontar novas áreas de investigação.

Dados os limites deste estudo, sugiro que outras investigações considerem novos contextos de estudo e busquem explorar o conhecimento intuitivo com profissionais de enfermagem de ambos os sexos, como também da área de saúde, analisando a sua expressão a

\section{REFERÊNCIAS BIBLIOGRÁFICAS}

1. Hansten R, Washburn M. Intuition in professional practice: executive and staff perceptions. J Nurs Adm 2000; 30(4):1859.

2. Lamond D, Thompson C. Intuition and analysis in decision making and choice. Image: J Nurs Scholarship 2000; 32(4):411-4.

3. King L, Appleton JV. Intuition: a critical review of the research and rhetoric. J Adv Nurs 1997; 26(1):194-202.

4. Rew L. Intuition in decision-making. Image: J Nurs Scholarship 1988; 20(3):150-4.

5. Sarvimaki A, Stenbock-Hult B. Intuition: a problematic form of knowledge in nursing. Scand J Caring Sci 1996; 10(1):23441.

6. McCutcheon HHI, Pincombe J. Intuition: an important tool in the practice of nursing. J Adv Nurs 2001; 35(5):342-8.

7. Marta IER, Berton AF. Intuição: o discurso da literatura. Rev Esc Enfermagem USP 1997; 31(1):89-95.

8. Silva AL. Experienciando o cuidado do cliente portador da síndrome da imunodeficiência adquirida, com base no sistema conceitual de Rogers. [Dissertação]. Florianópolis (SC): Pós-Graduação em Enfermagem/UFSC; 1990.

9. Silva AL. Cuidado transdimensional: um paradigma emergente. Pelotas: Ed. Universitária/UFPEL; Florianópolis: Programa de Pós-Graduação em Enfermagem/UFSC; 1997. 10. Benner P. From Novice to Expert: excellence and power in clinical nursing practice. Menlo Park (CA): Addison-Wesley; 1984.

11. Leners DW. Intuition in nursing practice. J Holistic Pract 1992; 10(2):137-53.

12. Goldberg P. O que é intuição e como aplicá-la na vida diária. São Paulo (SP): Cultrix; 1983.

13. Effken JA. Informational basis for expert intuition. Adv Nurs Sci 2001; 34(2):246-55.

14. Burns N, Grove S. Understanding nursing research. Philadelphia (PA): WB Saunders; 1995.

15. Lincoln Y, Guba EG. Naturalistic inquiry. Newbury Park (CA): Sage; 1985.

16. Rew L, Barrow EM. Intuition: a neglected hallmark of nursing knowledge. Adv Nurs Sci 1987; 10(1):49-62. partir das relações de gênero.

As evidências empíricas indicam que profissionais que aprenderam a se guiar por suas intuições se diferenciam dos demais pela melhor qualidade de sua prática $^{(2,10-11)}$, o que justifica a incorporação da intuição no cuidado de enfermagem.

\section{AGRADECIMENTO}

A autora agradece o Conselho Nacional de Desenvolvimento Científico e Tecnológico - CNPq, pelo apoio financeiro dado à pesquisa.

17. Guerrit P. Perception in nursing: the value of intuition. Holistic Nurs Pract 1987; 1(3):63-71.

18. Easen P, Wilcockson J. Intuition and rational decisionmaking in professional thinking: a false dichotomy? J Adv Nurs 1996; 24(4):667-73.

19. Miller M, Babcock D. Critical thinking applied to nursing. St. Louis: CV Mosby; 1996.

20. Schraeder BD, Fischer DK. Using intuitive knowledge in a neonatal intensive care nursery. Holistic Nurs Pract 1987; $1(3): 45-51$. 